\title{
Preventive, Mitigating and Treatment Strategies for Containing or Ending The COVID-19 Pandemic
}

\author{
Jianqing $\mathrm{Wu}^{1}$, Ph.D., J.D. and Ping Zha ${ }^{2}$, M.D. (Chi. Med.) \\ Originally posted February 26 2020, last update April 23, 2020
}

(Preprint for comments, NOT published)

Correspondence: tempaddr2@atozpatent.com

1. End the Incurable Era (Independent researcher for cause), P. O. Box 689, Beltsville, MD 20704. www.igoosa.com.

2. Independent Researcher (Not affiliated with any entity), can be reached by using the above address.

Keywords: coronavirus, COVID-19, viral reproduction, immune response, low temperature injury, lung damages, cold flu influenza, deep breathing exercises, diet, emotion stress, lifestyle

\section{ABSTRACT}

To understand great disparities in disease outcomes between COVID-19 patients, we explore infection and host responses in kinetics. From existing data, we deduced a model that the lungs are damaged by rapidly rising flow resistance as a result of retaining white blood cells in lung tissues. The retention of white blood cells is initially triggered viral infection but aggravated by injuries caused by low temperature. Lungs are initially damaged by fluid leakage, rapidly followed by extruding blood into alveolar spaces. The step of blood extruding is predicted to take place in a very short time. Our simulations show that as little as $0.1 \%$ retention of white blood cells in the lungs can lead to their failure in 5 to 10 days. The small degrees of imbalance implies that this imbalance could be corrected by a large number of factors that are known to reduce flow resistance. The model implies that the top priority is maintaining blood micro-circulation and preserving organ functions in the entire disease course, especially after the virus has spread the whole lungs. From exploring a large number of hypothetical infection modes, we propose preventive, mitigating and treatment strategies for ultimately ending the pandemic. The first strategy is avoiding exposures that could result in widespread damages to lungs and taking post exposure mitigating measures that would reduce disease severity. The second strategy is reducing death rate and disability rate from the current levels to one tenth for infected patients by using multiple factors health optimization method. The double 
reduction strategies are expected to generate a series of chain reactions that favor mitigating or ending the pandemic. Some reactions include a big reduction of the amount of viral discharges from infected patients into the air, the avoidance of panic, chronic stress and emotional distress, and cross-infections which are expected in quarantines. The double reductions would have a final effect of ending the pandemic.

\section{INTRODUCTION}

At the time of writing this article, there are 75,285 total cases, with 2,009 deaths in 26 countries [1]. At least 29 countries have reported cases. In the U.S., 15 infection cases were reported in Arizona, California, Illinois, Massachusetts, Texas, Washington, and Wisconsin [2]. After the outbreak of the COVID-19 virus, the research community seek strategies to contain the pandemic.

The outbreak of SARS in 2003 led to a near pandemic with 8096 cases and 774 deaths reported worldwide, resulting in a fatality rate of $9.6 \%$ [3]. Since the outbreak of MERS in April 2012 up until October 2018, 2229 laboratoryconfirmed cases have been reported globally, including 791 associated deaths with a case-fatality rate of $35.5 \%$ [4]. In the past, we have seen outbreaks of Ebola, Chikungunya, and Zika [5].

Coronavirus is an RNA virus, which can mutate rapidly. The genetic plasticity of RNA viruses is one of the main obstacles for the control of the diseases they cause [6]. Even if vaccine is available, vaccine is expected to have only partial protection due to the direct exposure of lung cells to viral particles [7]. Difficulties to contain such a pandemic is implied in consistent failure to control influenza viruses. Influenza virus transmission is promoted by low temperature based on guinea pig model of influenza virus transmission. The mechanism(s) by which temperature and humidity alter transmission outcomes remains unclear, but may include multiple effects acting at the level of the host, the virus, and the respiratory droplet $[8,9]$.

We previously discussed strategies for reducing damages to lungs in infected patients [10]. What is more important is containing or ending the pandemic because it affects people life, disrupts world trade order and casts uncertainty in human life. We noted that final resolution of the infection depends on immune responses, while risk of death and degree of disability depend on the severity of infection and efforts of reducing lung damages. Some important factors are initial infection severity or manner of infections, viral reproduction speeds, immune responses, waste removal balance, etc. The first two factors depend on viral-host interactions and a large number of factors; and waste removal efficiency depends on inflammation degree, lung micro-network condition, and organ capacities. One important factor is health-seeking behavior, 
which plays a key role in controlling influenza [11]. While influenza could be caused by non-coronavirus, the dynamics of infection and disease processes are presumed to be similar to those of COVID-19.

We explore strategies for reducing infection chances and death rate. We then consider how the double reductions lead to favorable chain of reactions.

\section{MODEL DEVELOPMENT}

\section{A. Knowledge and Facts Considered in the Models}

Following knowledge and facts are considered and relied upon in developing our multiple phase infection modes and lung damage models.

1. Viral infection steps and immune responses

Yoo et. al provide a review of knowledge of viral infection, and host responses [12]. The review summarizes current understanding of the triggering of innate and adaptive immune responses to infection, viral clearance, damages restoration, and virus-associated other sequelae. However, the current knowledge is limited to disease mechanisms viewed from a static point of view. No attempts have been made to evaluate their speeds and the impact of their speeds. In real cases, what can make differences to disease outcomes is the order of those different events, their timings, their relative speeds, and factors that affect their speeds.

2. Lung damages

Lung damage in SARS has been extensively discussed [13]. On gross examination, the lungs were edematous and increased in weight. In most cases, they showed extensive consolidation.

During the first phase of the disease ( 7 to 10 days), the lungs display extensive edema, glossy membrane formation, collapse of alveoli, scaling of alveolar epithelial cells, and fibrous tissue in alveolar spaces. Features of fibrous organization of diffuse alveolar damage (DAD) appear after about 10 to 14 days, such as interstitial and airspace fibrosis and pneumocytic swelling. When in 2 to 3 weeks, dense septal and alveolar fibrosis were seen. A direct correlation is observed between the extent of fibrosis and the duration of the illness.

DAD can progress to organizing pneumonia, which may result in permanent pulmonary fibrosis or resolve with the restoration of normal lung structure and function. The outcome depends on host factors, the severity of lung injury, and whether or not the inciting cause is corrected. Free radical damage from high levels of oxygen is common cause of DAD in severe patients. 
Above findings are confirmed in a COVID-19 case report [14]. The patient had dry cough on Jan 14 (day 1 of illness) but kept working until Jan 21 . The patient died from a sudden cardiac arrest later. Histological examination showed bilateral DAD with cellular fibromyxoid exudates. The right lung showed evident desquamation of pneumocytes and hyaline membrane formation. The left lung tissue displayed pulmonary oedema with hyaline membrane formation suggestive of early-phase ARDS. Interstitial mononuclear inflammatory infiltrates, dominated by lymphocytes, were seen in both lungs. Multinucleated syncytial cells with atypical enlarged pneumocytes characterized by large nuclei, amphophilic granular cytoplasm, and prominent nucleoli were identified in the intra-alveolar spaces, showing viral-induced structural changes. Overactivation of T cells, manifested by increase of Th17 and high cytotoxicity of CD8 T cells, accounts for, in part, the severe immune injury in this patient.

\section{Classical infection probability model}

Infection chances are studied by classic model using MOI. MOI is the ratio of the number of virus particles to the number of target cells present in a defined space. The actual number of viruses or bacteria that enter any given cell is a statistical process: some cells may absorb more than one infectious agent while others may not absorb any. The probability that a cell will absorb $\mathrm{n}$ virus particles or bacteria when inoculated with a particular MOI can be calculated for a given population using a Poisson distribution [15]. When an MOI of 1 (1 viral particle per cell) is used to infect a population of cells, the probability that a cell will not get infected is $\mathrm{P}(0)=36.79 \%$, and the probability that it be infected by a single particle is $\mathrm{P}(1)=36.79 \%$, by two particles is $\mathrm{P}(2)=18.39 \%$, by three particles is $\mathrm{P}(3)=6.13 \%$ and so on. As the MOI increases, the percentages of cells infected with at least one viral particle also increases: 1.0, 63.2\%; 3.0, 95.0\%; 5.0, 99.3\%; and 8.0, 100.0\%.

In this model, an implied assumption is each virus has the same probability to enter into any of target cell. The model does not take into account the speed of each infection. As we will show, disease outcome depends on the race between an apparent viral reproduction and immune response, and the immune-caused damages are related to their phase lag. Second, we have observed that the lungs have about 500 million alveoli (range: 274-790 million), and exposure to virus sources is not uniform. Due to differences in geometry, locations, and blood local circulation condition, an exposure to viral particles source could result in one, several, tens, hundreds, to millions infections or different parts of infections. Thus, the classic Poisson model cannot be used to model kinetics.

\section{Independent action hypothesis and collective infection}

One classical assumption is independent action hypothesis (IAH): every virus particle operates independently from other viral particles [16]. Zwart et al. developed a probabilistic framework for testing this hypothesis and demonstrated that two virus-insect systems tested, IAH is supported by the data. The mathematical model is mainly based on Poisson distribution. This model 
concerns only probability outcome. Like in a drawing trial, the model does not take into account any factors that alter infection probability in a real time and factors that affect specific cells, a portion of cells, or the entire lungs. This model finding however provides support that infection could be caused by a single virion.

Increasing evidence indicates that viral spread is often facilitated by groups of viral genomes, such as polyploid virions, aggregates of virions, virioncontaining proteinaceous structures, secreted lipid vesicles, and virus-induced cell-cell contacts. These multi-genome structures may promote virus-virus interactions and the evolution of social-like traits $[17,18,19,20]$. Those properties imply that infection requires a higher concentration of viruses, and may require more time to form infectious structure.

\section{Airborne viral particles and their transmission}

Bacteria and viruses can travel through the air. When someone sneezes or coughs, tiny mucous droplets filled with viruses or bacteria scatter in the air. The expelled air can travel at the speed of 75-100 miles per hour [21]. In air samples collected from a school during an influenza season, influenza A virus was detected in densities ranging from $2.0 \times 10(-1)$ to $1.9 \times 10(4)$ (gene copies $\mathrm{m}-3$ air) [22]. The study also establishes that viral infection time depend on viral concentration. Airborne exposure time is inversely related to virus gene copies. Based on the assumption that one TCID 50 is equivalent to about 300 PCRdetectable IAV RNA copies. The study establishes that infection time and concentration is 1 min for 11,161-281,250, 30 mins for 372-9,375, 1 hour for 186-4,688, 3 hours for 62-1,563, and 8 hours for 23-586.

The particle size of influenza A virus was studied [23]. Influenza A virus was detected in all particle size ranges in quantities ranging from 5.5x10(2) (in particles ranging from 1.1 to $2.1 \mu \mathrm{m}$ ) to $4.3 \times 10$ (5) RNA copies $/ \mathrm{m}(3)$ in the largest particles $(9.0-10.0 \mu \mathrm{m})$. PRRSV was detected in all size ranges except particles between 0.7 and $2.1 \mu \mathrm{m}$ in quantities ranging from $6 \times 10$ (2) (0.4-0.7 $\mu \mathrm{m})$ to $5.1 \times 10(4) \mathrm{RNA}$ copies $/ \mathrm{m}(3)(9.0-10.0 \mu \mathrm{m})$. Porcine epidemic diarrhea virus was detected in all particle sizes and in higher quantities than IAV and PRRSV ranging from $1.3 \times 10(6)(0.4-0.7 \mu \mathrm{m})$ to $3.5 \times 10(8)$ RNA copies/m(3) $(9.0$ $10.0 \mu \mathrm{m})$. In the case of IAV and PRRSV, viruses were isolated from particles larger than $2.1 \mu \mathrm{m}$.

Porcine epidemic diarrhea virus (PEDV) can travel a long distance, air samples were collected both from a room containing infected pigs and at various distances from the outside of swine farms experiencing PEDV outbreaks [24]. Infectious PEDV was found in the air from experimentally infected pigs and genetic material of PEDV was detected up to 10 miles downwind from naturally infected farms at the concentration of $7.98 \times 10(3)$.

Viruses were detectable in association with aerosolized particles. Proportions of positive sampling events were 69\% for PEDV, 61\% for HPAIV, and 
8\% for PRRSV. For all 3 viruses, higher numbers of RNA copies were associated with larger particles [25]. Influenza virus RNA was detected in air samples collected between 1.5 and $2.1 \mathrm{Km}$ away from the farms with viral levels significantly lower at $4.65 \times 10$ (3) RNA copies $/ \mathrm{m}^{3}$ [21].

Pigs can be a source of infectious aerosols of Influenza A virus. Such aerosols can be exhausted from pig barns and be transported downwind to a long distance [26]. Some of these viral particles are infectious. The viral concentration depends on viral source and distance from the source. The viral concentration is $5.71 \times 10(7)$ in oral fluid, $8.32 \times 10(4)$ inside air, and $4.57 \times 10(4)$ in exhaust air. Relative to oral fluid, virus in inside air is diluted by about a thousand and exhausted air has a further lower viral concentration.

\section{B. Limitations In Existing Concepts and Research Methods}

To find strategies to contain the pandemic, we need to examine concepts and methods used in current research.

To predict whether an infection takes place, an accepted method is using a known range of TCID 50, which is the number of viral particles that induce infection in $50 \%$ of inoculated tissue culture cells. This number may be far too higher than what could cause an infection. In a single cell organism, 50\% may be a reasonable number for determining chance of individual infection. However, it is not a suitable number. In a multicellular organism, as long as one cell is infected, the virus may cause the disease. If one person is infected, the disease could be passed onto others by chain of infection.

Probability model based on Poisson distribution makes an assumption that virus infects cells at the same probability. This model does not consider how fast an infection can take place and what alter the speed of infection process. In reality, viral particle number always affects viral infection speeds. The number or viral concentration affects the chance for viruses to contact a target cell. When thousands of viruses "dance" on a cell, the time for completing the first viral entry is shorter than the time required for one virus particle to enter the cell.

Small probability theory is widely used in statistical analysis in medicine. Any method that is based on the small probability theory (e.g., 5\%) cannot be used as a measure to break up the chain of infection for a pandemic. If the method could result in false results by a small chance, the method cannot contain the pandemic.

Weather an influenza can be transmitted by airborne particles and what concentration can cause infection has been studied for years [27]. No conclusion has been reached. Lack of conclusion is not surprising because nature does not create diseases by a binary scale, which is imposed by human will. Whether airborne particles transmit viruses depend on a large number of factors such as viral nature, viral concentration, viral out-of-the-body time, exposure time, humidity and temperature, host health, and even luck. Nevertheless, those 
animal model studies provide useful information that allows us to understand viral exposure risks.

For the above reasons, strategies intended to extinct viruses will be extremely difficult. The virus may transmit by airborne particles; may infect animals, and may stay in human body for restarting a new outbreak. For a similar reason, a cure by using vaccine and a synthetic drug would depend on luck. The rapid mutations can defeat acquired immunity; and belated immune responses may fail to protect certain persons who have been infected before.

Reasonable strategies comprise two lines of measures. A first line of measures is preventing and substantially reducing infection incidences. They naturally include everything that can be used in medicine, but include everything else. If infection incidence rate is reduced to one tenth relative to the imagined background, the pandemic can be controlled easily. Second line of measure is reducing the death rate. If the death rate is reduced to one tenth of the current rate or blow $1 \%$, the risk of the disease will be tolerable. Since death rate and infection modes are related, some measures may affect both. If a measure can make infections less severe, infected patients collectively discharge less amount of airborne particles into the air. This will have an effect of making infection source smaller. When the overall infection rate and death rate are reduced to tolerable, people will not be panic; quarantine is not necessary; cross-infection in quarantines can be avoided; and mind will become the powerful component for fighting the disease.

Medical treatments are developed without considering viral concentrations, viral exposure duration, route of infection, host conditions, hostviral interactions, the phase lag between viral infection and immune responses, the stage of the disease, etc. Such treatments cannot effectively contain the pandemic because those factors actually determine infection chances, disease spreading, disease severity, and death risk.

\section{Hypothetical Viral Infection Modes}

Since our focus is on speed of viral infection and reproduction and the speed of damage process, we need to consider all probable modes of infections. Based on indications found in studies and news reports $[12,13,14,28,29,30$, 31 , etc.], we propose most probably infection modes or manners and then explore how different modes affect disease progression speeds and final outcomes.

1. Particles containing viruses enter the nose, they are trapped by nose hairs, thrown out by the centrifuge force generated by nasal turbinates, trapped by mucus and propelled by cilia vibrations. The particles that land on the respiratory track are finally destroyed by macrophages that reside on the membrane. If a small number of viruses enter epithelial cells, they are destroyed by host responses. No infection takes place. 
2. All facts are same as scenario 1, except that some viral particles enter epithelial cells of bronchi, and, with time delays, they start reproducing and later discharging cell content to blood. There is no independent infection in the lung. The viruses from discharged cells get into the bloodstream and activate the adaptive immunity. The virus from the blood is accompanied by rapidly increased antibody concentration to contain viral reproduction.

3. All facts in scenario 2 plus the following: a small number of viral particles enter the lung alveoli because the first line defense mechanisms fail to retain, capture, or inactivate them. The viral particles in alveoli dance on the epithelial cells. After various delays, they make entries and, after delays, they start reproducing. Disease severity depends on the number of alveoli involved and the number of infection cells in each alveolus. Infected alveoli are injured. If a sufficient water leaks out in an alveolus, it collapses. Only a small number of alveoli is involved, initial symptom is thus mild.

4. All facts in scenario 3 except that a large number of alveoli are infected. Many of the infected alveoli collapse as a result of leaked fluid or discharged cell contents, the lungs are unable to maintain normal function; and the patient experiences shortness of breach. The disease severity depends on the scale of damages to alveoli. Additional or independent infections may take place on brochini and other body parts.

5. All facts in scenario 1 except that a small number of alveoli are infected. Disease severity depends on how fast the viruses from the initially infected alveoli reinfect other alveoli, and whether other alveoli are infected by independent viruses.

5a. All facts in scenario 5 plus the fact that other alveoli are reinfected by viruses from the prior infected alveoli. Disease severity depends on how fast the viruses reinfect other alveoli and the scale of reinfections.

5b. All facts in scenario 5 plus the fact that alveoli are infected by external viruses independently. Disease severity depends on the scale of successive infections, and the timings of their infections.

6. A large number of alveoli are infected by external viruses in a very short time window. If bronchi are not infected, the patient experiences dry cough. If bronchi are also infected, the patient produces wet discharge. The lungs may fail quickly. Disease severity depends on the portion of alveoli involved and their timings of infections.

7. The facts in $5,5 \mathrm{a}, 5 \mathrm{~b}$, and 6 , plus the fact that the patient is burdened by other inflammation. A bad secondary cold, allergic reaction of foods, the side effect of synthetic drugs, excessively high oxygen administration, and extremely poor environment conditions such as low temperature and high humidity aggravate the patient's condition. 
8. The facts in 7 plus senior age. Old people's lung functions have declined by as much as 30\% compared with young people; their blood vessels are less elastic so that they more easily retain white blood cells which are responsible for the failure of pulmonary circulation.

The above infection scenarios are summarized in the following table followed by a list of influencing factors.

Table 1 Two Phases Infections, Repeating Infections, and Influencing Factors

\begin{tabular}{|c|c|c|c|}
\hline $\begin{array}{l}\text { Infection } \\
\text { Case No. }\end{array}$ & $\begin{array}{l}\text { Infection } \\
\text { Phases and } \\
\text { Sites }\end{array}$ & $\begin{array}{l}\text { Defense } \\
\text { Mechanisms \& } \\
\text { Timings }\end{array}$ & Influencing Factors \\
\hline 1 (no risk) & $\begin{array}{l}\text { Bronchi } \\
\text { exposure; no } \\
\text { infection }\end{array}$ & Innate immunity & $\begin{array}{l}\text { Micro-vascular network, } \\
\text { health condition, temperature, } \\
\text { humidity, RIGHT nutrition, } \\
\text { etc. }\end{array}$ \\
\hline 2 (mild) & $\begin{array}{l}\text { Bronchi } \\
\text { infection }\end{array}$ & $\begin{array}{l}\text { Innate immunity } \\
\text { and acquired } \\
\text { immunity }\end{array}$ & Same as 1 above \\
\hline $\begin{array}{l}3 \text { mild to } \\
\text { risky }\end{array}$ & $\begin{array}{l}\text { 1st: bronchi } \\
2^{\text {nd }} \text { : lungs }\end{array}$ & $\begin{array}{l}\text { Innate immunity } \\
\text { and acquired } \\
\text { immunity }\end{array}$ & $\begin{array}{l}\text { Time lag between two } \\
\text { infections; viral concentration, } \\
\text { particle form, scale of } \\
\text { exposure, micro-vascular } \\
\text { network, patient health, } \\
\text { temperature, humidity, blood } \\
\text { pH, etc. }\end{array}$ \\
\hline 4 (risky) & $\begin{array}{l}\text { 1st: bronchi } \\
2^{\text {nd }} \text { lungs (a } \\
\text { large scale). }\end{array}$ & $\begin{array}{l}\text { Innate immunity } \\
\text { and acquired } \\
\text { immunity }\end{array}$ & $\begin{array}{l}\text { Same as } 3 \text { above, plus the } \\
\text { scale of lung infection. }\end{array}$ \\
\hline 5 (risky) & $\begin{array}{l}\text { 1st: lungs } \\
\text { (limited) } \\
\text { Opt: bronchi }\end{array}$ & $\begin{array}{l}\text { Innate Immunity } \\
\text { acquired immunity }\end{array}$ & $\begin{array}{l}\text { Viral concentration, particle } \\
\text { form, exposure, micro- } \\
\text { vascular network, patient } \\
\text { health, temperature, humidity, } \\
\text { blood pH, etc (as common } \\
\text { factors) }\end{array}$ \\
\hline $\begin{array}{l}5 a \\
\text { (deadly) }\end{array}$ & $\begin{array}{l}\text { 1st: lung } \\
\text { (limited), } \\
\text { successive } \\
\text { infections }\end{array}$ & $\begin{array}{l}\text { Innate immunity } \\
\left(2^{\text {nd }} \text { infection takes }\right. \\
\text { place after acquired } \\
\text { immunity develops })\end{array}$ & $\begin{array}{l}\text { Poor air ventilation, improper } \\
\text { manner and repeating } \\
\text { exposure to self-virus, plus } \\
\text { common factors. }\end{array}$ \\
\hline
\end{tabular}




\begin{tabular}{|c|c|c|c|}
\hline $\begin{array}{l}5 \mathrm{~b} \text { (more } \\
\text { deadly) }\end{array}$ & $\begin{array}{l}\text { 1st: lung: } \\
\text { limited } \\
2^{\text {nd }} \text { lungs } \\
\text { (independent } \\
\text { infections) }\end{array}$ & $\begin{array}{l}\text { Innate immunity } \\
\left(2^{\text {nd }} \text { infection take }\right. \\
\text { place before } \\
\text { acquired immunity } \\
\text { develops })\end{array}$ & $\begin{array}{l}\text { Continue exposures, poor air } \\
\text { ventilation, lack of protection, } \\
\text { plus common factors. }\end{array}$ \\
\hline $\begin{array}{l}6 \text { (very } \\
\text { deadly) }\end{array}$ & $\begin{array}{l}\text { 1st: lung: } \\
\text { (whole lungs) }\end{array}$ & $\begin{array}{l}\text { Innate immunity } \\
\text { (dry cough as the } \\
\text { initial signs, } \\
\text { acquired immunity } \\
\text { is too late). }\end{array}$ & $\begin{array}{l}\text { Extensive exposure, lack of } \\
\text { protection, repeat exposures } \\
\text { in short time, especially } \\
\text { under cold and humid } \\
\text { environment, plus common } \\
\text { factors. }\end{array}$ \\
\hline \begin{tabular}{|l} 
\\
(more \\
deadly)
\end{tabular} & $\begin{array}{l}\text { Any of } 5,5 a, \\
5 b, 6 \text { plus } \\
\text { inflammation- } \\
\text { aggravating } \\
\text { factors. }\end{array}$ & $\begin{array}{l}\text { Innate immunity; } \\
\text { acquired immunity. }\end{array}$ & $\begin{array}{l}\text { use of inflammation-triggering } \\
\text { foods, synthetic drugs, plus } \\
\text { respective factors mentioned } \\
\text { for each scenario. }\end{array}$ \\
\hline $\begin{array}{l}8 \text { (most } \\
\text { deadly) }\end{array}$ & $\begin{array}{l}7 \text { plus senior } \\
\text { age }\end{array}$ & $\begin{array}{l}\text { Innate immunity; } \\
\text { acquired immunity. }\end{array}$ & $\begin{array}{l}\text { In addition to the above } \\
\text { factors, reduced usable organ } \\
\text { capacity, and reduced blood } \\
\text { vessel elasticity. }\end{array}$ \\
\hline
\end{tabular}

We assume that viruses may exist in airborne particles, some of which are capable of reaching and landing on alveoli. Some viral particles enter the lung alveoli notwithstanding the general belief to the contrary. The viruses may land on one to $\mathrm{N}$ epithelial cells of the alveoli. Most of them cannot immediately enter cells, but may stay there. With time passing and by strike of luck, a virus may make an initial entry into a cell. Infections may take place in one to $\mathrm{M}$ alveoli. Since we concern viral spread speed, the number of infected cells and the number of initially infected alveoli are both important.

We do not stress viral spread by viruses from the circulating blood. This infection mode is always a possibility. However, this mode is less important because viruses are diluted and checked by white blood cells in blood.

If the lungs inhale a large number of airborne particles, more of the alveoli may be filled with airborne particles, and more viruses may enter epithelial cells. High viral concentration can provide better chances for viruses to enter cells because they provide more contact opportunities. Regardless of how the viruses act in the initial infection, high concentration increases the infection speed in terms of number of entries per unit time. The time from the exposure to viral entry is noted as Te. 
After a virus has entered a cell, the virus stays in the cell for time (Tl). In this time, the virus adopts itself to the cell. Host condition affects the time length.

Some of the infected cells may discharge viruses or transmit viruses by cell-to-cell contact. Some viruses get into bloodstream and travel to bone marrows to activate adaptive immunity. It takes 4 to 6 days to develop detectable antibody concentration that has a power to protect the lungs. However, some patients may not develop strong antibody responses even after 4 weeks of illness [32].

If the number of initial infections is very limited, the viral population is expected to grow slowly. The damage to the lungs would be localized in a short time window. If a large number of alveoli are infected at substantially same time, the disease is expected to progress rapidly. We expect to see great differences between one seed site, thousands of seed sites, and millions seed sites.

Other organs and cell types that may be infected include mucosal cells of the intestines, tubular epithelial cells of the kidneys, neurons of the brain, and several types of immune cells, and certain organs may suffer from indirect injury $[12,13,14]$. However, we focus on the lungs in this study because lung damages are the common causes of death and disability.

\section{Repeated Infections and Development of Chronic Disease}

The total disease time courses we have observed vary from a few days to more than month, but involved damages are found in most part or the entire lungs. We suspect that different infection modes or manners are mainly responsible for dramatically different outcomes.

The disease severity depends ultimately on the portion of lung alvoeli that are destroyed by viral-triggered actions. A well accepted assumption is that virus enters a cell or a site followed by cell-to-cell spread. The scale of alvoeli destruction obviously depends on the number of infection points ("seed points"), their spatial locations in the lungs, and their timings relative to the immune response. Their collective effects must be viewed in light of the minimum lung function required to sustain life. Viral spread the entire lungs by repeated infection including independent infections of lung cells by newly airborne viruses, reinfection of healthy lung cells by the viruses from infected lung cells or brochini, reinfection of lungs cells from viruses traveling in blood, etc. All of the viral spread modes differ in infection points, their spatial locations and their timings relative to immune responses.

The viral spread speed depends on the infection seed number, their locations and infection timings. Infections of a large number of alveoli is much worse than infections of a limited number of alveoli. A uniform distribution of infection points in the whole lungs is worse than the same number of infection points only in a part of the lungs. Studies show that lungs in the patient have 
different localized damages [13]. Initial infection of lungs is worse than late infection, reinfection, or independent infection of lung cells. The importance of the three parameters is not any less simply because a final result is that "all alveoli are infected". What makes dramatically different outcomes is how fast the viruses spread to all alveoli and how severe the final damage is.

The lungs perform both inhaling and exhaling breath cycles [17]. When the lungs exhale, they drive air from lung alveolar spaces to bronchi and finally to trachea. The air exits from the nose. However, some of the exhaling air remains in primary bronchus, trachea and nostrils as the dead space. Each breath volume is about $500 \mathrm{~mL}$ for an an adult, with a dead space of about 150 $\mathrm{mL}$. When the lungs inhale, external air inhaled is mixed with the air in the dead space. Due to limited size of breath, the inhaled air could reach only tertiary bronchi; and most particles are trapped on bronchi membrane; some pass into alveoli as airborne particles by the alveoli ventilation. Breathing cycles are like pumping actions to spread viruses from infected cells to uninfected cells and from infected alveoli to non-infected alveoli.

Before infected cells start discharging cell contents, outgoing air may contain viruses in very low concentration equivalent to that of the background air. After the patient shows signs of infection, exhaled air contains viruses. Tidal (normal) breathing can contain virus [28]. Exhaled influenza virus RNA generation rates range from 3.2 to 20 influenza virus RNA particles per minute and over $87 \%$ of particles exhaled were under $1 \mu \mathrm{m}$ in diameter. In each inhaling cycle, the viral particles are diluted by 3 to 4 times. Normal breathes redistribute about 1 to 6 RNA particles per minute within the lungs. In a closed small room, the viral concentration can rapidly rise (add about 28,800 RNA copies/day for influenza virus per day). If we consider extra discharges from coughing and sneezing, air in a small close room can be real infection source that can reinfect healthy lung cells of the same patient.

Most viral particles distributed in reinfections are prevented by the first line defense. Those that land on alveoli may be killed by alveoli macrophages. The lungs have about 20 million macrophages, they may be able to take care of a small number of viral particles. Only about one macrophage for about every 1020 alveoli. It is a riddle how macrophages move around and reach viral particles and infected cells. Some viruses that have landed on alveoli may lose activity for other reasons. Those that survive stay for some times before reproducing. The first-phase infection takes place without activating the immune system; but the repeated infections may be caused by discharged viruses or independent viral sources. At the time of reinfections, some discharges get into the bloodstream. After reinfections take place, the reinfecting viruses encounter rapid immune response. In each of those scenarios, viral particle number is always a determinant factor: the lungs can take care of only a small number of invading viruses, but fail to deal with too many of them. 
The effects of reinfections on disease outcomes depend on previously infection degree and locations, inflammation degree, lungs' remaining capacity, and the immune response timing. Reinfections at early stages may damage more alveoli due to weak immune responses. A large scale of simultaneous lung reinfections could be lethal to patient with limited lung remaining functions. Reinfections at a late stage may have limited harm if lungs still have ample function. The immune response catches up with the viral reproduction speed and eventually contains viral reproduction.

Controlling successive reinfections is particularly important in several situations. First, if patient immune systems are compromised, reinfections can cause more viral damages. Second, for patients with limited usable lung functions, a large scale of successive reinfections can cripple more alveoli. Third, a widespread reinfections cause more serious inflammation and increase local blood pressure to extrude blood into alveolar spaces. If reinfections cause the whole lungs swelling, it is impossible to dilate blood vessels because there is no room for them. This may result in completely blocked pulmonary circulation. Finally, reinfections may aggregate diseases if reinfection is caused by additional viruses or different viral genome types. To improve disease outcomes, air must be well ventilated so that viral concentrations are lower enough to substantially slow down the reinfection processes.

The first-phase infection may comprise many individual infections at different times. We regard them as the first phase infection as long as they take place before the immune response is sufficiently powerful. The second phase infection may also comprise a series of individual infections at different lung location and in different times. After reinfections start, self-generated viral contractions may be much higher than viral concentration in ambient air.

It is anticipated that infections in some patients will become chronic diseases. Chronic diseases may be caused by immune compromise, excessive poor micro-vascular system, and formation of local structures which prevent the immune cells from clearing viruses completely.

\section{E. Progressively Degrading Lung Damage Models}

When lung alveoli are filled with water, the alveoli collapse due to the surface tension of water [21]. Alveoli can also be damaged by depositing viscous materials.

1. Inflammation-driven progressive lung damage model

Immune cells pass through capillaries by deforming themselves and squeezing through [31]. There is a great size discrepancy between the mean diameter of circulating leukocytes $(6-8 \mu \mathrm{m})$ and that of the pulmonary capillaries $(\sim 5.5 \mu \mathrm{m})$. Except platelet $(4 \mu \mathrm{m})$, all other white blood cells including HL-60 cells $(10.2 \mu \mathrm{m})$, erythrocyte, monocyte, and neutrophil (all at about $7.5 \mu \mathrm{m}$ ), and lymphocyte $(6.3 \mu \mathrm{m})$ are bigger than the mean pore size of capillaries. The model 
study found that retention time depends on cell stiffness and cell size in a complex manner. The study provides several hints: First, cell retention time depends on elasticity of capillaries. Second, the micro-vascular network of capillaries can be substantially jammed: when the fluid contains particles of different sizes, they can jam the pores. Finally, the fluid viscosity is an important factor. For example, platelets aggregation can raise flow resistance even though platelets are smaller than the pores of the capillaries.

A large number of resident macrophages are found in all kinds of diseased tissues [12, 13, 33, 34, 35]. Asbestotic lesions are characterized by macrophagic accumulation, fibroblast proliferation, and collagen deposition. The accumulation of a large number of macrophages can be attributed in part to their large size $(15-20 \mu \mathrm{m})$. The origin and differentiation cues for many tissue macrophages, monocytes, and dendritic cell subsets in mice, and the corresponding cell populations in humans, remain unclear [29]. Migration of monocytes is similar to elastic cats squeeze through expansible small door holes. After monocytes enter the tissue, some of them cannot get out due to increased friction. Some become larger macrophages. The tissue is like a filter to catch them. Figure 1 shows how the retention of white blood cells is responsible for damages to the lungs.
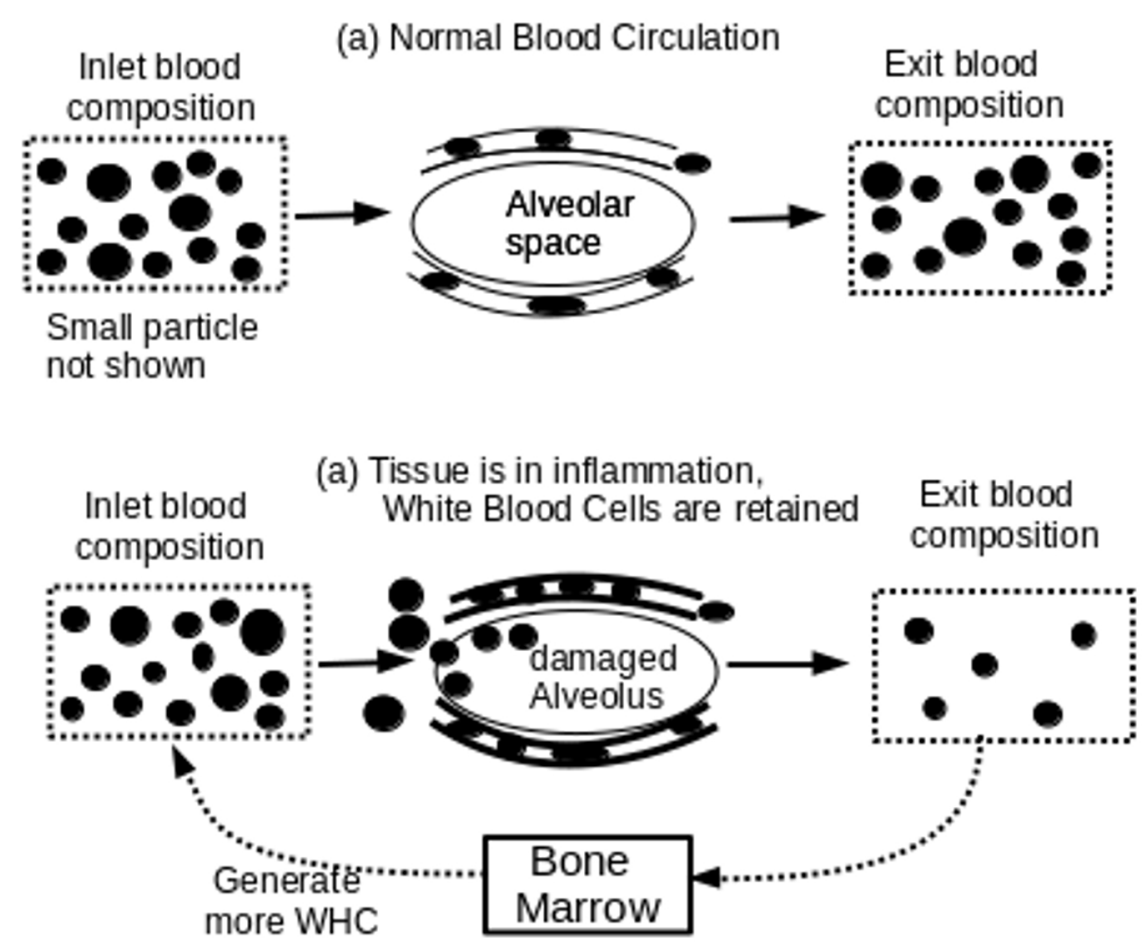

Figure 1, diagram (a) shows how white blood cells squeeze through capillary network with much smaller pores. Diagram (b) shows that when the 
tissue is in inflammation, the wall of capillaries is changed and the white blood cells will met with increased friction. Some large white blood cells are retained and thus result in higher local blood pressure. Initially, water leaks out from the blood vessels and passes through inter-cellular or interstitial spaces to reach the space of the alveolus. When local blood pressure rises further, white blood cells break the blood vessels and squeeze between epithelial cells to reach the space of the alveolus.

When tissue is in inflammation, the endothelium actively participates in controlling blood flow, and affect permeability, leukocyte infiltration, and tissue edema [35, 36]. The changes in epithelial cells disrupt blood homeostasis by increasing capillaries resistance. Other changes include flow dysregulation, thrombosis, and capillary leak [35]. The elevated local blood pressure causes the blood to break epithelial cells and get into alveolar spaces. The leak of blood results in swelling of the tissue, reduce room for capillaries to expand, and has an equivalent effect of reducing capillary deformity or elasticity. The tissue has increased flow resistance to blood circulation and retain white blood cells for too long. From a dynamic view, the white blood cells remain in the tissue for too long with some bigger cells being permanently caught in the tissue. The net result is that the number of white blood cells (including all decomposed cells) exiting from the lungs is fewer than that of white blood cells entering into the lungs.

If the inflammation is of a limited degree, the slower migration speed has an effect of extending white blood cells' dwell time so that they have more opportunities to encounter and engulf infected cells and foreign matters. However, on a long term basis, the number of entering white blood cells must be same as the number of exiting white blood cells in any given time. We refer this requirement as white blood cells transport balance.

If the inflammation is not resolved, the lung blood circulation degrades. The inflamed tissue keeps dynamically retaining white blood cells. By perpetual accumulative effects, white blood cells are accumulated on the inflamed tissue leading to high flow resistance. A reduction of the white blood cells in the blood then causes bone marrows to generate more white blood cells [14]. When newly arrived white blood cells travel through the lungs, they are again caught and retained dynamically. The leaked blood and accumulated white blood cells eventually occupy substantially all volume spaces in the lungs. Extruded blood fills all voids in the lungs, the flow resistance of the lungs reaches the maximum, having an effect of shutting down the pulmonary circulation. The end result is inevitable heart failure or multiple organs failure.

The worst damage is on lung alveoli $[13,14]$. Each alveolus is surrounded by a capillary network. Most alveoli are filled with viscous materials and white blood cells. If a sufficient number of alveoli have been filled by extruded blood materials, the lungs become consolidated and has diminished capacity. The patient cannot breathe and die if lung function is lower the threshold of death. 
Severe inflammation inevitably leads to congestion of lung tissue. Healthy lungs are highly elastic and have ample rooms for alveoli to expand during breathing cycles. After the white blood cells are caught and accumulated in alveolar spaces, the lung circulation become worse and worse due to tissue swelling. Normal blood circulation in lung tissues is increasingly replaced by extremely-slow inefficient diffusion process. As a result, some lung cells die from lack of energy and oxygen. When high concentration of oxygen is administrated, free radicals may cause additional damages to lung cells. To fill the dead tissue, lungs generate fibroblastic cells.

The total volume of lung alveolar spaces is $2000-3000 \mathrm{~mL}$. The heart of an adult person pumps blood at 5 litters/min; the pulmonary flow is essentially same as cardiac output. White blood cells make up approximately $1 \%$ of the total blood volume and red blood cells $40-45 \%$. Assuming that only $0.1 \%$ of the white blood cells are retained for any time increment, the retention rate would be equivalent to $0.05 \mathrm{ml}$ volume of white blood cells per minute. The total volume of blood extrudes increase with time as shown in the following table.

Table 2 Percent of Lung Alveolar Spaces Filled By Blood Extrudate at Various Times (Based on 1/1000 retaining volume of white blood cells)

\begin{tabular}{|r|r|l|l|l|}
\hline $\begin{array}{l}\text { Retained Vol. } \\
\text { (ml/Min) }\end{array}$ & $\begin{array}{l}\text { Time } \\
\text { (min) }\end{array}$ & $\begin{array}{l}\text { Time } \\
\text { (days) }\end{array}$ & $\begin{array}{l}\text { Total Extrudate } \\
\text { Vol (ml) }\end{array}$ & $\begin{array}{l}\text { Vol (\%) of Alveoli } \\
\text { Space }\end{array}$ \\
\hline 0.05 & 1 & 1 min & 0.05 & 0.0025 \\
\hline 0.05 & 60 & 1 hour & 3 & 0.15 \\
\hline 0.05 & 1440 & 1 day & 72 & 3.6 \\
\hline 0.05 & 7200 & 5 days & 360 & 18 \\
\hline 0.05 & 14400 & 10 days & 720 & 36 \\
\hline 0.05 & 28800 & 20 days & 1440 & 72 \\
\hline 0.05 & 43200 & 30 days & 2160 & Over \\
\hline
\end{tabular}

Lung Volume $=2000 \mathrm{ml}$, Blood Flow Rate $=5 \mathrm{Lit} / \mathrm{Min}, \mathrm{WBC}=1 \%$ and white blood cells retention rate $=0.1 \%$.

The filled volume can also be estimated by computing the BWC volume. In a normal adult, there are 4.3-10.8 $\times 10(9)$ white blood cells per liter of blood. Assuming $0.1 \%$ of WBCs ( 1 in 1000 white blood cells) are retained in any given time, we get a similar trend below. We use Lung Volume $=2000 \mathrm{ml}$, Blood Flow Rate $=5$ Lit/Min, Cell Vol=1000 cu. $\mu \mathrm{m}$.

Table 3 Percent of Lung Alvoelar Spaces Filled By Blood Extrudate at Various Times (based on cell volume)

\begin{tabular}{|c|c|c|c|c|c|c|}
\hline $\begin{array}{l}\text { Ret. WBC } \\
(/ \mathrm{min})\end{array}$ & $\begin{array}{l}\text { Cell Vol. (c. } \\
\mu \mathrm{m})\end{array}$ & $\begin{array}{l}\text { Ret Rate } \\
(\mathrm{mL} / \mathrm{min})\end{array}$ & $\begin{array}{l}\text { Total Time } \\
\text { (mins) }\end{array}$ & $\begin{array}{l}\text { Total Time } \\
\text { (hours) }\end{array}$ & $\begin{array}{l}\text { Total Extrudate } \\
\text { Vol. (mL) }\end{array}$ & $\begin{array}{l}\text { Vol (\%) of } \\
\text { Alveolar Spaces }\end{array}$ \\
\hline 35000000 & 1000 & 0.035 & 1 & $1 \mathrm{~min}$ & 0.035 & 0.00175 \\
\hline 35000000 & 1000 & 0.035 & 60 & 1 hour & 2.1 & 0.105 \\
\hline
\end{tabular}




\begin{tabular}{|r|r|r|r|r|r|r|}
\hline 35000000 & 1000 & 0.035 & 14401 day & 50.4 & 2.52 \\
\hline 35000000 & 1000 & 0.035 & 72005 days & 252 & 12.6 \\
\hline 35000000 & 1000 & 0.035 & 1440010 days & 504 & 25.2 \\
\hline 35000000 & 1000 & 0.035 & 2880020 days & 1008 & 50.4 \\
\hline 35000000 & 1000 & 0.035 & 4320030 days & 1512 & 75.6 \\
\hline
\end{tabular}

The discrepancy between the two methods lies in the approximate volume of white blood cells and estimated mean cell volume of white blood cells. The absolute cell volume is not important because the lungs are actually filled by all blood extruded materials (not just big cells). However, the large white blood cells play bigger roles in retaining white blood cells.

When the lungs cannot maintain white blood cells transport balance, the white blood cells are accumulated in alveolar spaces. The lungs may fail within five to ten days. This happens when a big part of alveolar spaces are filled by extruded blood or the leaked liquid diminishes lung function. If the retention rate of white blood cells increases to $1 \%$, the patient may die in one to two days. Second, in both above computations, we did not consider two self-aggravating effects. Retained white blood cells and lung swelling are expected to make lung circulation progressively worse; and the resultant failure to maintain energy metabolism further aggravates inflammation and diminishes the heart ability to maintain required circulation.

In reality, the lungs fail more rapidly than predicted by the linear relationship. Considering the rapidly aggravating effects, we estimate that the dynamic retention rates of white blood cells could be $0.01 \%-0.1 \%$ initially, increase to $0.1 \%$ to $1 \%$ when the lungs lose most function, and could finally reach near theoretical $100 \%$ (diffusion only and heart arrest). This rapid increased flow resistance is consistent with the rapid disease course from shortness of breath to death. A patient may die within a week of initial signs of infection [14]. The small departure from the imbalance implies that the problem can be corrected by using right methods in the earliest time.

2. Physiological injury of low temperature to the lungs

The extruding of blood into alveolar spaces implies that the local blood pressure is elevated. We suspect that temperature plays a vital role in causing or aggregate this problem.

The systolic pulmonary pressure is about $25 \mathrm{~mm} \mathrm{Hg}$ and diastolic pulmonary pressure is about $8 \mathrm{~mm} \mathrm{Hg}$ with the mean pulmonary arterial pressure being about $15 \mathrm{~mm} \mathrm{Hg}$. The capillaries and pulmonary lymphatic system normally maintain negative pressure in the interstitial spaces. In a normal situation, a negative pressure in interstitial spaces is maintained by normal negativity, the flow caused by lymphatic pumping, and net osmotic pressure. Extra fluid that have been on alveoli is sucked back to the lung interstitium through the small openings between epithelial cells. Damage to the 
capillary membrane causes leakage of fluid and plasma proteins. The edema of the interstitium results in a rise in interstitial pressure, which causes immediate rapture of the epithelium. In the classic model, edema is caused by infection.

We show that low temperature can revere the pressure in the interstitial spaces by aggravating the retention of white blood cells in the capillary network. For a segment of capillary, flow resistance can be determined by equation $\mathrm{R}=$ $8 \eta 1 / \Pi r^{4}$. If large white blood cells can move with blood fluid, they merely raise resistance. However, if one or more white blood cells are retained in the capillary or move very slowly along the capillary pore, the fluid of blood flows by squeezing though the void between the surface of retained white blood cells and the capillary wall. The retention has the effects of dramatically reducing actual radium $\mathrm{r}$ and raising local capillary pressure. Normal capillary pressure is about $7 \mathrm{~mm} \mathrm{Hg}$. A low temperature cause it much higher. A low temperature change the normal interstitial pressure from negative to positive. The retention of white blood cells can have enough power to defeat all known safety factors. The rise in the interstitial pressure leads to rapture of epithelium of alveoli and fluid move toward to alveoli walls. At this stage, the damages may be reversible if the problem is corrected.

Those retention of white blood cells can have a global impact if it is serious enough. The pulmonary pressure is determined by the flow resistance of the entire lungs. When a sufficient number of capillaries is blocked, the total flow resistance must rise; and slow-moving white blood cells in capillaries also reduce the extensible volume of the blood vessels in the lungs. This elevated pulmonary pressure in turn raises capillary pressures for all capillaries networks by different degrees. The interstitial pressures are directly related to the capillary pressure. If the capillary pressure is high enough, the outward pressure will be larger than inward pressure. There must be a point at which the pressure at the interstitial space is changed from the normal negative to a positive value. After this point, the retention of white blood cells aggravated by low temperature can have a global impact on the lungs. For very similar reason, infection has a similar effect on the interstitial pressure. Infection of a sufficient number of alveoli can cause damages to all alveoli including those that have not been infected.

Even if fluid has been leaked onto substantially all alvoeli, the damages may be still reversible if a negative interstitial pressure can be restored as soon as possible. When the lungs could not perform their function for maintaining life, the initial attempt is to race heart until the heart fails. Extra pumping will further raise the pulmonary pressure briefly. The elevated pulmonary pressure than squeezes blood into any spaces in the entire lungs including all alveoli space. This may take a short time, possibly in a matter of less than an hour.

Our models show that infection of a part of alveoli can adversely affect the whole lungs through raising the pulmonary pressure when capillaries are partially blocked or retarded. Low temperature is the main aggravating factor because it can greatly increase the retention rate of white blood cells in alveoli. 
When infection and low temperature work together, they can cause widespread initial damages to all alveoli though raising the pulmonary pressure to a point reversing the interstitial pressure. An initial fluid-induced damages will trigger the trigger the heart to raise pulmonary pressure as an attempt of recovery. A further rise in the pulmonary pressure will force blood extrude into all voids in the lungs and the spaces of all alveoli.

The elevated local pressure also implies that blood viscosity plays a central role in lung damages. The departure from the normal white blood cells balance is so small that it could be amendable. Red blood cells count, platelets aggregation degree, and natures and amounts of other materials affect blood viscosity and thus the flow resistance and actual pressures.

In the classic model, both temperature role and retention of white blood cells is not recognized. Our modified models imply that controlling infection alone is not enough if the infection is predicted to cause serious inflammation that can impair the white blood cell transport balance. Intervening points should go beyond viral control and include improving pulmonary circulation, reducing blood viscosity, improving renal function, and protecting liver function.

Many other mechanisms may be attributed to tissue damages. Examples include apoptosis, innate immunity, and ER stress response that may be modulated by human coronavirus [37]. Both the host and the virus can manipulate innate immune mechanisms as a form of defense or evasion strategy $[38,39]$. In cases of prolonged and irreversible ER stress, apoptosis mechanisms are triggered [39]. During viral infections, ER stress response is induced. The utilization of the ER elicit immense burden, causing the host to mount unfolded protein response as its antiviral response [41]. Those mechanisms do not explain the large number of accumulated white blood cells and extruded viscous materials in lungs.

3. Lung damages induced by insufficient lung function

If the lungs are unable to perform required functions, degraded energy metabolism speeds up lung deterioration and leads to failure of major organs such as heart, kidneys, and liver. Those processes are shown in Figure 2.

(c) All right reser

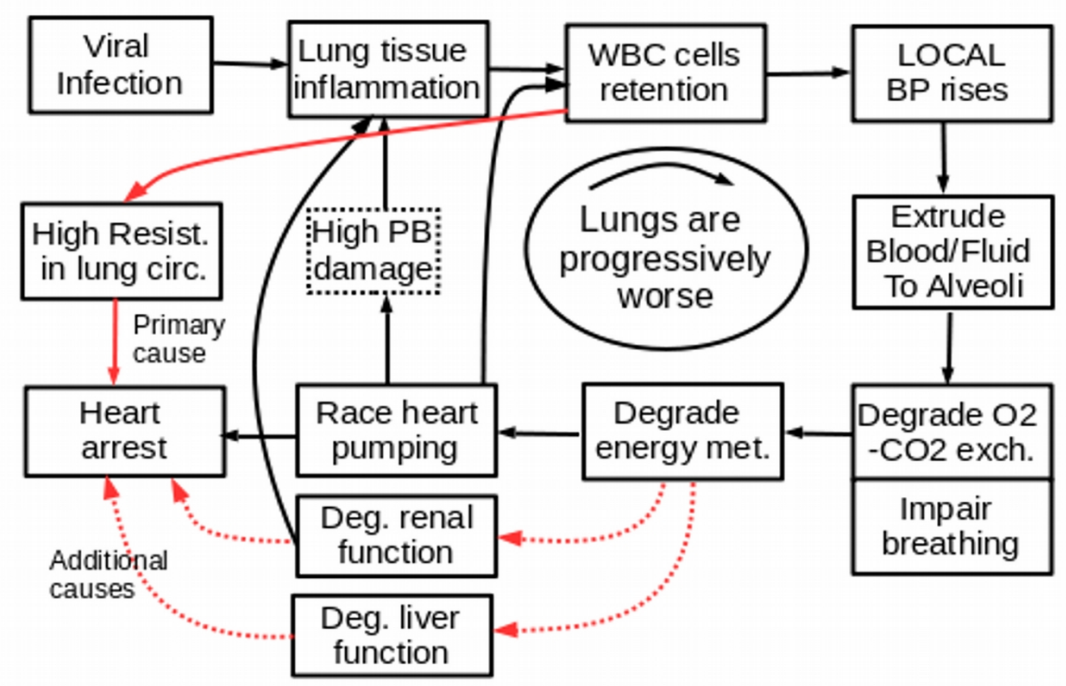


Figure 2 shows how viral infection triggers the retention of white blood cells and causes damages to alveoli as indicated by the round circular arrow. The damages to alveoli results in higher flow resistance and degrade energy metabolism. The increased flow resistance and impaired heart, renal and liver function inevitably result in heart failure (as indicated by red arrows).

If a small portion of the alveoli are initially infected, only the infected alveoli may be damaged in the early time. The damaged alveoli cannot be compressed and expanded as normal. They add mechanical resistance to breathing processes. However, people can survive with only part of functional lungs [42, 43, 44]. If inflammation is limited, inflammation-triggered poor blood circulation may damage only the infected tissue and some surrounding tissues.

Severe and irreversible damages to lungs are triggered by extensive and widespread infections. When a sufficient number of alveoli are infected by the virus, the virus-caused inflammation causes white blood cells to accumulate in infected tissues. The inflammation causes the lungs to further reduce function. The inflammation-driven process steadily brings the lung's usable function down, but may not necessarily cause immediate lung failure.

If the inflammation drives the lung function to below the threshold (40\% of the maximum or whatever threshold for the person), the lungs are unable to deliver required oxygen. Oxygen insufficiency affects all major organs including the heart, the liver, and the kidneys. The heart will have less power to pump and the kidneys have a diminished capacity to clear inflammation and metabolic wastes. All wastes are accumulated at faster rates, and, in turn, further promote inflammation. The degraded blood circulation results in accumulation of more white blood cells and more metabolic wastes, and cause more damages. This implies that lost balance in waste removal aggravates the white blood cell transport imbalance.

While inflammation is the initial culprit, the usable capacity of the heart, the kidneys and the liver determines the body's ability to resolve inflammation. When inflammation-driven damage is coupled with heart, kidneys and liver deterioration, the lungs degrade faster. When the whole lungs severely swell, the flow resistance of the capillaries network is high. The blood pressure in the pulmonary arteries is expected to rise; and eventually pulmonary flow resistance is too high to maintain the pulmonary circulation. It is inevitable that the heart fails due to excessive pulmonary flow resistance and lack of energy in the heart. The strategy is improving blood circulation as early as possible in the entire disease course. Measures include those to strengthen vital organs. 
Even if lungs fail to maintain blood circulation by a small margin initially, the condition can degrade as more and more white blood cells are added into the tissue. When the lung circulation is sufficiently bad, lung cells die and their voids are filled by fibroblastic cells $[13,14]$, which have no function but add resistance to breathing force.

This model implies that lung damages could be triggered by viral damages without triggering immune responses. Before acquired immune response has reached a sufficient level, virus-induced inflammation may be enough to cause white blood cells retention, leading to eventual lung failure and heart arrest.

This lung damage model explains the vital role of temperature in lung micro-circulation. The flow of blood in the lung capillaries is controlled by precapillary sphincters near arterioles, or by the sizes of capillary pores. When temperature is lower, blood vessels and capillaries in lung tissues are constricted [45]. A lower temperature results in smaller pore sizes of capillaries. A lower temperature also raises blood viscosity and slows down blood circulation. Temperature is a critical factor in preventing infection, reducing the severity of infection, promoting recovery, and reducing damages to lungs.

The model also explains the role of humidity in disease outcomes. The role of humidity on influenza is known [8]. When the COVID-19 outbreak took place, it was a cold and humid season. Humidity affects alveoli ventilation. When the humidity is high, water molecules coming from alveoli cells cannot be brought out efficiently. Thus, more water molecules stay on the inner walls of alveoli. For those alveoli with fluid leakage, high air humidity hinders recovery of their function. The water layers on alveolar walls also interfere with oxygen-carbon dioxide exchange and thus adversely affect the lungs by degrading energy metabolism.

The model can explain the role of blood viscosity, mechanical vibrations, and salt role. A large number of factors affect blood viscosity. Those factors affect disease development in the entire disease courses. It is a common sense that objects jammed at a bottleneck of a bag can be facilitated by making mechanical vibrations. A suitable degree of activities and motions can disrupt the machinery used in RNA replication. This effect can be inferred from its impact on cell cycles in dinoflagellates [46]. COVID-19 requires formation of envelop proteins [47]. This is in accord with the observed vulnerability of obese persons to many viruses presumably due to lower physical activities [75-83].

The model can explain the roles of heart, lung, liver and kidneys. Their functional capacities determine how well patients can tolerate viral-caused inflammation. Old people are more vulnerable to lung infection because their usable lung function has been reduced by about $30 \%$ when they reach the age of $90[42,43,44]$, and their blood vessels are less elastic.

The damage model also explains the special benefits of doing consistent deep breathing exercise. The increased expansion and contraction of thoracic 
cage and the diaphragmatic movements can increase the force to squeeze interstitial fluid from the arterial side to the venous side and force slow-moving blood out of the lungs by squeezing distensible blood vessels; breath-induced mechanical vibrations facilitate the passing of white blood cells through lung tissues; active motion of the exercise can raise lung local temperature with triple benefits including reducing blood fluidity; the increased air exchange improve alveolar ventilation and thus brings out more of the leaked water from alveolar spaces; and finally, the exercise can improve the function of the CNS or the brain region that regulates lung functions. The exercise can be used to offset some of the adverse effects in the entire disease course.

The model also explains the role of chronic stress and emotional distress on disease outcomes [48-57]. When person is in a relaxed state, the blood circulation is improved and white blood cells encounter less friction.

Due to differences in influencing factors, some patients die with a few days after experiencing first signs, some can survive for much longer times, most people can recover, and some have little or no symptoms. The differences can be explained by the cumulative effects of above-mentioned factors, but cannot be determined by randomized controlled trials [58].

\section{F. Future Recurrent Lung Infections}

The unique structure of lungs make them especially vulnerable to infections. We predict that a person could be infected by the same or similar viral species after the prior infection has resolved. After an infection has resolved, the antibody concentration declines rapidly. While a small number of B cells exist as memory cells, they provide limited benefits. Assuming that a massive of airborne viral particles are inhaled into the lungs, infections can take place at multiple sites without the full protection of the immune system. It is possible that exposure to high concentration of the same virus may cause serious diseases.

Some patients die within only a few days after the initial signs of infection. This is because infection starts on the side of cells that are away from blood flow. In contrast, viral infections of other organs are originated by viruses that are traveling in blood. Hepatitis C, HIV, etc. travel through blood. In those cases, the activation of the cellular immunity takes place before the virus starts infecting target cells.

\section{STRATEGIES FOR CONTAINING THE COVID-19 PANDEMIC}

Based on the infection modes and lung damage model, we propose preventive, mitigating, and treatment strategy to achieve double-ten reductions.

We proposed double-tenth reduction strategies to contain or mitigate the pandemic. The main promise of this strategy is that disease process is addressed 
in a quantitative manner rather than in a binary scale. The double tenth reduction strategies are reducing incidence rate from an imagined background rate to one tenth and reducing the current death rate of infected patients to one tenth. When incidence rate is reduced to one tenth, the total disease population can be reduced dramatically. When the death rate is reduced to one tenth or below $1 \%$, a disease would be like a bad influenza. The double reductions will generate a series of positive chain of reactions. When the death rate is tolerable, people will not be panic, cross-infection in quarantine is avoided, and adverse impacts of panic, emotional distress will not aggravate the pandemic. Deaths attributed to cross-infections in hospitals, improper and wrong treatments, and unexpected adverse side effects will be minimized. Those changes will contribute to further reduction of death rate.

\section{A. Avoiding Exposure and Reducing Exposure Severity}

Attempt to contain the COVID-19 pandemic by breaking the chain of infection could be difficult. Virus can travel up to 10 miles. In animal infection cases, no direct contact exists between different animal farms but epidermic can pass from a farm to another. Even though viruses are slowly inactivated when they travel in air, one cannot expect all viral particles lose infectious power. An "extincted" virus may be revived by animals carrying it. This risk is implied by related virus SARS-CoV, which can transmit through species such as Himalayan palm civets, raccoon dogs, Chinese ferret badgers. Moreover, 60 novel bat coronaviruses were identified in bats in various regions of the world [62]. A new outbreak may be restarted by patients who carry the virus as chronic infections. Vaccine is expected to have only partial protection due to expected delays in immune responses and viral mutations. So, it would be as difficult as containing an influenza outbreak.

The chances of infection depend on viral source, viral concentration, viral activity level, manner or routes of infections, times of exposures, duration of exposure, health condition, post-exposure remedial measures, post-infection mitigating measures, innate immunity, immune system response, etc.

1. Preventive measures should be consider to increase personal ability to resist COVID-19 infection. The best strategies are strengthening the innate immunity, blood micro-circulation in the lungs, and immune surveillance function. Due to the phase lag between the lung infection and the immune response, maintaining strong innate immunity is the most important. Since immune cells migrate into lung tissues by squeezing themselves, improving lung micro-vascular networks is the most important measure to mitigate damages to the lungs. A large number of things can be used to increase the density of capillaries, reduce the fat coats in capillaries, increase elasticity of capillaries, increase the space for accommodating blood vessel expansion, and reduce blood viscosity. Those measures should be taken before an infection.

2. Avoid exposure to low temperatures, avoid excessive fatigues, and avoid exposure to cold and humid environment in an outbreak season. If exposure to 
virus is suspected, avoid exposure to temperature until the infection is resolved or no infection has taken place in reasonable days.

3. Reduce inhalation of viral particles and wash hands frequently. Breathing viral-containing air only one time is better than breathing 100 times. Exposure to an infectious environment for many days is worse than exposure for one day. Shortening time of exposure if exposure is unavoidable, and strictly reduce the total number of inhaled viral parties to the minimum for a time period.

4. The manners of initial infection and repeating infections are vitally important. One cannot avoid viruses in a city where a large number of people have been infected. Risk of infections cannot be evaluated according to the yesor-no rule. Do not think that every infection is same. An important strategy is avoiding exposure to a massive viral particles in a short time. People should learn avoiding direct exposure to air containing fresh droplets and airborne particles, avoid breathing air from the vicinity of infected patients, and shortening exposure duration.

5. A large number of factors could be used in several days before exposure to several days after exposure, during treatment, during recovery, and even after recovery. General guidance can be developed for reducing direct lung damages in all kinds of lung infections, and detailed guidance can be tailored for this virus when more knowledge about the virus is known.

6. In an outbreak reason, reduce time in public places, avoid getting too closer to strangers, walk away from air flow or wind containing coughed droplets and avoid getting close to strangers who are talking. Withhold breath for seconds to avoid coughed air and resume breathing after walking a few steps away from the coughing area.

7. Stores, schools, and hospitals should take measures to reduce human density or improve air ventilation. Ventilation condition is especially important in areas where customers stand in line. If fresh air cannot be provided, a ventilation system should be used to filter out viral particles from the air. A reduction of viral concentration and removal of large particles from the air can make differences even though their benefits are not be reflected in disease incidence rates.

8. Airborne particles differ greatly in infection power and infection scale. Fresh droplets from the lungs of persons under infection are the most risky sources; droplets from the mouth of an infected person is the second; air exhaled from an infected person may contain a small number of viral particles; viruses in in particles lose infectious power with time and the decay of viral activity shapely depends on temperature. The risk level of dusts generated from things that have been used by infected persons would depend on how viral particles are diluted. We recommend use of ballpark dilution factor: the fresh viral discharge from an infected person as a reference concentration, and dilution by at least 1,000 times 
to a million times can make differences. Double dilution by a million time each can make viral source safer for health people.

9. Per the classical model, a low viral concentration and a long exposure time would achieve a similar level of infection. However, under this two phase infection model, extended duration of the infection has an effect of postponing some individual infection actions to later times. The delays cause some viral reproduction activities to take place after the immune system has been scaled up. Later infections are less harmful. Therefore, disease severity cannot be accurately predicted by simple product rule.

10. Lung infection and non-lung infection may be caused by two independent exposures. Their relative timings and routes are important. If a patient gets a lung infection first and later gets an eye infection from other source, the eye infection does not mitigate the lung infection. If the eye infection takes place a few days before the lungs infection, the eye infection may work to shorten the phase lag between lung viral development and the immune response. If the eye infection is caused by a lung infection, the eye infection only add a burden to the immune system. If a person is expected to expose the lungs to high concentration of virus inevitably, a possible strategy is infecting the digestive track so that the immune system can protect the lungs.

\section{B. Strategies for Mitigating Infection and Lung Damages}

From infection modes and the lung damage models, we found many intervening points for altering disease outcomes. Based on disparities in disease severity among different patients, a large number of measures could be used to make differences. An adverse outcome is always the result of accumulated effects of viral-induced damages. The patients can have a long time window to defeat the accumulative adverse effects (except in a small number of cases, patients die within one to two days of the earliest signs).

1. From exposure to the viruses to experiencing the first signs, most viruses cannot enter the lungs and some of them may take time to complete entries. A smallest number of viral entries is better as a general rule. Two viral entries are better than thousands of viral entries at once. Successful viral entries take chance, require host interactions, often at the mercy of innate responses. Naturally, different viruses enter lung cells or bronchus membrane at different locations in different times. It may take hours to days for a small number viruses to make initial entrance; and some viruses may succeed after they get help from newly arrived viruses or lucky assistance from the person (e.g., exposure to low temperature). Thus, exposure to the virus is just a start point, but not a gameover point. Many potential methods could be used to reduce the number of viral entries. Even through the whole lungs are expected to be infected by the virus, intervening measures can delay viral entries and reproduction and thus reduce damages to the lungs. 
2. Post exposure remedial measures include simple things like cleaning nose and irrigating the mouth and nose to remove as many trapped viral particles as possible to reduce further viral entries.

3. Effort should be made to stop sequential exposure to external viruses. Before any virus is released to the bloodstream, the body is still vulnerable to continuous infections in the lungs. This measure is much powerful than using antiviral and antibiotic to control independent and cross-infections.

4. Adjust body conditions in the latent periods. Viral reproduction requires interactions between viruses and hosts [20, 37, 59, 60, 61, 62], but none of the research findings has been used in treatments. In multiple factors health optimization approach, it is not required that each of selected factors has a definite effect as defined by a binary scale. The following should be considered:

(1) Temperature is the most important factor. It is absolutely the first priority to avoid exposure to low temperature. It affects blood vessel stricture, blood viscosity, blood vessel pore size, etc. Keeping warn is the most important measure in the fight against cold, influenza and any lung infections and is important before exposure to the virus, in the latent time, during treatment, and during recovery.

(2) Low humidity facilitates removal of water layer on the alveolar walls and promotes oxygen and carbon dioxide exchange and thus improve the lungs' function to maintain waste removal balance and mitigate the congestion of white blood cells in lung tissues.

(3) Increase water intake to reduce blood viscosity. A large number of other factors can be used to reduce blood viscosity. Certain foods such as garlic and a large number of herbs can be used to reduce platelet aggregation or improve blood circulation. Right level of salts can reduce blood viscosity by influencing ironic strength. Intake of more water with moderate salts can increase the ability to disperse viral-generated wastes, cell debris and metabolic by-products into the circulating blood.

(4) Increase mechanical vibrations of the lungs. Sound-uttering, an ancient healing art, can help lungs relax, thus facilitating the passing of white blood cells through the capillaries network. It is best used in early phrase, after the reinfection phase, and during the recovery phase. However, sound uttering in the reinfection time windows may facilitate viral spreading. One best bet is avoiding uttering violent and explosive sounds in the reinfection time window. We have shown that deep breathing exercises is the most powerful method for fight against lung infection. It has been used in China, India, Japan, Korean, etc. as the primary healing art for thousands of years. This exercise can be used in a bulk of times to counter the virus-caused white blood cell retention.

5. Use right dietary, environmental, and lifestyle factors to mitigate infection severity and lung damages. Vitamins A, C, E, antioxidants, selenium, 
etc. protect lung cells from the injuries of free radicals [64-74]. Lifestyle and body condition also affects human vulnerability to viral infection [75-85]. Chronic stress affects immune responses [86, 87]. A large number of factors can be used correctly to alter disease outcomes if they are combined.

\section{Strategies For Reducing Lung Damages and Risk of Death}

The infection modes and damage models imply two different strategies in different stage of disease. In the early phase or before the virus has spread to the whole lungs and the patient's vital organs have ample redundant functional capacities, the measure is inhibiting, slowing down viral reproduction, viral spread and viral reinfections. This should be done as soon as possible. After the whole lungs have been infected, anti-viral drugs in late stages should be avoided after the vital organ capacities have declined to disability levels. Instead, a sound strategy is taking measures to reduce tissue inflammation, reduce flow resistance, keep waste removal balance and strengthen vital organs in the entire treatment period.

1. Use all safe and non-conflicting factors in favor of inhibiting viral reproduction, promoting innate immunity, boosting immune response, and improving the lung blood circulation as discussed in Sections A and B above.

2. Mitigate or slow down re-infections by patient-self-originated viruses. What is critically important is slowing down viruses spread to the whole lungs. Good emotion, good air ventilation, warn body temperature, low air humidity, and good life manners can slow down the reinfection process. Slower reinfection speeds have an effect of extending the total time for the viruses to spread to the whole lungs. Sequentially sporadic reinfections have less burden on the whole lungs than synchronized large-scale infections. Longer delays in successive infection timings result in reduced viral burden and reduced level of inflammation, thus reducing lung damages and risk of death. If the reinfection time is extended from several hours to a few days, it could make a difference to final outcome.

3. After at least some infected cells have discharged cell contents, couching and sneezing generate high-concentration viral sources for selfreinfection. In the early phrase or small time window, patients should avoid coughing, sneezing, and violent throat clearing activities as much as possible or taking any valid measures to inactivate viruses that are inhaled back. Such attempts can slow down viral spread speed. After the whole lungs have been infected, coughing can generate force to improve micro-circulation to facilitate white blood cells to pass through.

4. Measures are taken to reduce repeating infections or successive infections of independent viral sources. Slowing down reinfections is particularly important if the first infection is sufficiently serious so that additional lung infections may cause the lung interstitial pressure to become positive (the point for causing widespread damages to alveoli). Avoiding, reducing or slowing down 
lung reinfections is particularly important when the patient lung function has declined to a disability level.

5. Find and use measures that could improve the waste removal balance and encourage white blood cells to pass through lung tissues. Controlling parameters are temperature, air humidity, body hydration, mechanical motions, blood viscosity, and the functions of the heart, lungs, liver, and kidneys. Those measures should be taken as early as possible, and must be continuously used in the entire course of the treatment.

6. If the virus cannot be determined, doctors and patients should focus on degrading signs and take measures to arrest further degradation of blood circulation. The strategy is not replacing a first measure with a second measure when the first measure appears to fail. Properly chosen measures should not be disused simply because they appear to fail to work. Every bit of incremental improvement can slow down disease development speed, but its benefits cannot be determined objectively or subjectively. Such measures can slow down the viral spread in the lungs, delay the arrival time of the critical point of damaging lung alveoli, help the patient live longer, and allow the immune system to catch up.

7. In the fight against the infection, success or failure is a result of the speed race between viral reproduction and immune response and the timeaccumulated effect of damaging process caused by imbalance in white blood cell transport. In this race, delays in individual viral actions, advances in immune activities, and altered timings of individual immune activities must influence final outcomes.

8. Drugs may help slow down viral reproduction, maintain blood circulation, strength heart functions, etc. Patients should be advised that drug side effects can temporarily diminish the usable organ capacities of lungs, heart, liver and kidneys. When the lungs are under severe distress, even a moderate thrust by drug side effects can instantly cause death. Patients should appraise drug side effects wisely and should consider using factors with little risks.

9. Some medical treatments developed by population medicine should be reexamined in the context of those models.

(1) Antiviral drugs are effective only in the early stage when the functions of major organs are strong. When treatment is started within two days of becoming sick with flu symptoms, antiviral drugs can lessen fever and flu symptoms, and shorten the time of being sick by about one day. After the viruses have spread to the whole lungs, virus reproduction is limited by biological resources and immune responses. When patient's lung functions has approached disability level, such a drug may only burden the lungs by its side effects. Since a controlled trial is generally not used to study timing and phases problems, existing data should be rejected due to canceling out of the positive and negative effects. Using antiviral and anti-bacteria drugs in the later stage disease should be avoided. 
(2) We also question the measure of using drugs to lower body temperature. Body temperature is controlled by substance interleukin-1 (or leukocyte pyrogen) in the hypothalamus of the brain. Interleukin-1 is released from blood leukocytes and tissue macrophages that have digested viruses and bacteria [21]. Thus, raising set-point of temperature has an expected benefits of improving blood micro-circulation and facilitates immune cells transport balance. Lowering the body temperature may be justified only in situations that excessive high temperature could damage the brain. However, a better strategy is maintaining the lungs at a higher temperature but lowering the head's temperature by using a cooling bath.

(3) Using oxygen intake must be reasonable. While supply oxygen can improve lung function, it can cause widespread damages to lung cells and make inflammation even severe. The strategy is avoiding getting to that point and then using oxygen to cause widespread damages to lung cells.

(4) Medicine should explore drugs that can dilate blood vessels starting as soon as possible. However, side effects are always concern. If the blood circulation can be maintained, use of steroids should be avoided because steroids have caused severe damages to bones.

10. To maintain vital organ functions, herbs may be formulated to improve holistic health. Herbal formulations may include herbs that fight against the virus and inflammation, promote waste removal, and strengthen all major vital organs. The focus is improving blood micro-circulation in lungs. Synthetic drugs may be used to dilate blood vessels, but this should be used in the early stage. When the whole lungs have been consolidated, there is no room for the blood vessels to expand. We expect that the degree of lung size swelling seen in autopsy reports do not reflect the real degree of fluid retention.

\section{Case Outcome Disparities}

According to news, four family members died within a few days, but many people survive from repeating exposure environments. We see a pattern that disease outcome differences depend on how they take care of themselves. Based on our reading of a large number of patient self reports, we found that serious diseases are often associated with exposure or repeat exposure to low temperature (such as exposure to low temperature after work, taking a ride in an open pickup in freezing winter, lack of heating, etc. Some diseases are associated with life experience such as living at an abandoned warehouse in an attempt to avoid infecting family members. Some patients turn minor infections into repeated or serious infections by doing a series of wrong things. Some failed to take measures or ignored their signs for many days or a weak. By doing nothing, they lose the valuable time for intervening. Some bad results can be traced a series of mistakes. Others only await for magic drugs and vaccines. Others are treated with excessive antiviral drugs, belated and improper oxygen administration, and use of excessive steroids. The moderate death rate and high disability rate are a result of lack of treatment experiences and lack of health 
culture for addressing this disease. The great outcome differences imply that the diseases are responsive to many factors that can be used. Medical community should address each case in personalized medicine. It is clear that treatment protocols based on population-trial without focusing on exposure, disease timing, personal health, immune responses, lung micro-vascular networks, etc. cannot succeed. Most deaths can be avoided if we formulate right preventive, mitigating and treatment strategies. Even temperature alone can be enough to offset of 0.1 to $1 \%$ departures in white blood cell transport.

\section{E. Policy Implications}

Even though COVID-19 is novel, a great deal of related knowledge exists which could aid us in finding treatment strategies. Strangely, all basic research ends without exploring potential utilities of their findings. Temperature and humidity have been known for thousands of years, have been used in entire human histories, and have been confirmed in modern studies. Yet, they are still left out from modern treatments. The reason is that treatments using lifestyle, environmental, and physical factors, etc. do not help vendors generate profits and randomized control trials generate confusing and false results. This leaves only one revenue: finding a magic drug or vaccine. The population-based medicine creates wrong perception by pooling data from different patients, with different disease stages, different health conditions, and varying disease severity, etc. Our simulations show that only $0.1 \%$ departure from white blood cell transport balance could be fatal, but temperature alone can alter blood vessels diameters by a few percents. We have to found that temperature, humidity, physical state, emotion, nutrients can have ample power to change disease outcomes if they are correctly and persistently used.

The true risk of COVID-19 can be attributed to a small percent of persons with poor health or serious exposures. Bad disease outcomes come out due to wrong or improper treatments, leading to population panic, which ultimately becomes one biggest aggravating factor. Most bad disease outcomes are associated with severe low temperature injury, exposure to cold and humid environment, cross-infections, repeating infections, emotional distress, fears and stress, etc. If the disease is not contained or mitigated, the top priority is improving population general health AND learning how to avoid serious lung exposures and how to use those factors to make outcome different. Temperature, humidity, exercise, environment factors, lifestyle, diet and herbs, emotional management, etc. can be used to establish powerful protocols to contain or end the pandemic.

\section{F. Limitations of The Study}


Infection modes are deduced based on well established facts that cannot be refuted and there is no need to direct proof. Here, we reject an unproved belief that viral particles generally cannot directly reach deep lung tissues. This belief cannot withstand challenge from a probability theory in light of observed great disparities in diseased outcomes. The damage models (the low temperature injury and the retention of white blood cells) are deduced based on lung damages and are consistent with overwhelming irrefutable findings. Our models depart from the classic leukcytes recruitment theory (e.g., Chemotaxis, as directional locomotion of cells towards a source of a chemical gradient, first described by Pfeffer in 1884) for infection, tissue injury and immune reactions. Our models can explain the "drive force" which could not be explained in any existing model. However, our models still could not explain how the big white blood cells move around at the site of inflammation. Thus, a better understanding could be gained by future experiments designed to explore cell migration mechanisms and changes in the structure of pulmonary capillary networks in patients. Such knowledge will allow researchers to find better treatments to address the increased pulmonary flow resistance.

\section{FUNDING STATEMENT}

The author(s) declared that no grants were used in support of this research project.

\section{CONFLICT OF INTERESTS}

None

\section{ADDITIONAL INFORMATION}

Additional information is provided in a supplemental document and some information will be stored in igoosa online database.

This article may be used by any person for personal use as fair use; any use for research and academic exchanges is permitted by default.

\section{REFERENCES}


1. WHO, Novel coronavirus (COVID-19) situation as of 19 February 2020, 16:00 (CET) accessed at

http://who.maps.arcgis.com/apps/opsdashboard/index.html\#/c88e37cfc43b4ed3b af977d77e4a0667

2.CDC. Coronavirus Disease 2019 (COVID-19), Coronavirus Disease 2019 (COVID-19) in the U.S. Updated February 17, 2020 Accessed at https://www.cdc.gov/coronavirus/2019-ncov/cases-in-us.html

3. World Health Organization WHO. Summary of probable SARS cases with onset of illness from 1 November 2002 to 31 July 2003 2003. Available from: http://www.who.int/csr/sars/country/table2004_04_21/en/index.html.

4. World Health Organization WHO. WHO MERS-CoV Global Summary and Assessment of Risk, August 2018 (WHO/MERS/RA/August18) 2018. Available from: http://www.who.int/csr/disease/coronavirus infections/risk-assessmentaugust-2018.pdf?ua=1.

5. Parvez, M.K.; Parveen, S. Evolution and Emergence of Pathogenic Viruses: Past, Present, and Future. Intervirology 2017, 60,1-7.

6. Domingo E. (1997) RNA Virus Evolution, Population Dynamics, and Nutritional Status, Biological Trace Elements Research, 56: 23-30.

7. Domingo E., Holland J. J. (1997) 'RNA Virus Mutations and Fitness for Survival', Annual Review of Microbiology, 51: 151-78.

8. Anice C. Lowen, John Steel. Roles of Humidity and Temperature in Shaping Influenza Seasonality. Journal of Virology. July 2014 88:14,7692-7695

9. Lowen AC, Mubareka S, Tumpey TM, Garcia-Sastre A, Palese P. 2006. The guinea pig as a transmission model for human influenza viruses. Proc. Natl. Acad. Sci. U. S. A. 103:9988-9992. http://dx.doi.org/10.1073/pnas.0604157103.

10. Wu J. and Zha P. Treatment Strategies for Reducing Damages to Lungs In Patients with Coronavirus and Other Infections (February 6, 2020). Available at SSRN: https://ssrn.com/abstract $=3533279$;

https://www.preprints.org/manuscript/202002.0116/v1.

11. You S-H, Chen S-C and Liao C-M. Health-seeking behavior and transmission dynamics in the control of influenza infection among different age groups. Infect Drug Resist. 2018; 11: 331-343.

12. Yoo J-K, Kim TS, Hufford MM, and Braciale TJ. Viral infection of the lung: Host response and sequelae. J Allergy Clin Immunol. 2013 December; 132(6): doi:10.1016/j.jaci.2013.06.006. 
13. Gu J. and Korteweg C. Pathology and Pathogenesis of Severe Acute Respiratory Syndrome. The American Journal of Pathology, Vol. 170, No. 4, April 2007.

14. Xu Zhe, Shi L, Wang Y. et al. Pathological findings of COVID-19 associated with acute respiratory distress syndrome. The Lancet Respiratory Medicine. February 18, 2020. DOI:https://doi.org/10.1016/S2213-2600(20)30076$\underline{X}$

15. Ellis, Emory; Delbruck, Max. The Growth of Bacteriophage. The Journal of General Physiology. 1939, 22(3): 365-384.

16. Zwart MP, Hemerik L, Jenny S. et al. An experimental test of the independent action hypothesis in virus-insect pathosystems. Proc. R. Soc. B (2009) 276, 2233-2242.

17. Leeks A, Sanjuán R, and West SA. The evolution of collective infectious units in viruses. Virus Res. 2019 May; 265: 94-101.

18. Vignuzzi M., Stone J. K., Arnold J. J., et al. Quasispecies Diversity Determines Pathogenesis Through Cooperative Interactions in a Viral Population, Nature, 2006, 439: 344-8.

19. Shirogane Y, Watanabe S, Yanagi Y. Cooperation between different variants: A unique potential for virus evolution. Virus Res. 2019 Apr 15;264:6873.

20. Leeks A., Segredo-Otero E.A., Sanjuán R., West S.A. Beneficial coinfection can promote within-host viral diversity. Virus Evol. 2018;4/2

21. Guyton AC. The cough reflex, In Text of Medical Physiology ( $8^{\text {th }}$ Ed). W.B. Saunders Company pg 411-412 (various page rages).

22. Coleman KK., Sigler WV. Airborne Influenza A Virus Exposure in an Elementary School. Scientific Reports volume 10, Article number: 1859 (2020) Scientific Reports volume 10, Article number: 1859 (2020)

23. Alonso C, Raynor PC, Davies PR, Torremorell M.Concentration, Size Distribution, and Infectivity of Airborne Particles Carrying Swine Viruses. PLoS One. 2015 Aug 19;10(8):e0135675. doi: 10.1371/journal.pone.0135675. ECollection 2015.

24. Alonso C, Goede DP, Morrison RB, Davies PR, Rovira A, Marthaler DG, Torremorell M. Evidence of infectivity of airborne porcine epidemic diarrhea virus and detection of airborne viral RNA at long distances from infected herds. Vet Res. 2014 Jul 14;45:73. doi: 10.1186/s13567-014-0073-z.

25. Alonso C, Raynor PC., Goyal S, Olson BA, Alba A, Davies PR, Torremorell M. Assessment of air sampling methods and size distribution of 
virus-laden aerosols in outbreaks in swine and poultry farms. Journal of Veterinary Diagnostic Investigation 2017, Vol. 29(3) 298-304.

26. Corzo CA, Culhane M, Dee S, Morrison RB, Torremorell M. Airborne Detection and Quantification of Swine Influenza A Virus in Air Samples Collected Inside, Outside and Downwind from Swine Barns. PLoS One. 2013 Aug 8;8(8):e71444.

27. Arruda AG, Tousignant S, Sanhueza J, Vilalta C, Poljak Z, Torremorell M, Alonso C, Corzo CA. Aerosol Detection and Transmission of Porcine Reproductive and Respiratory Syndrome Virus (PRRSV): What Is the Evidence, and What Are the Knowledge Gaps? Viruses. 2019 Aug 3; 11(8). Epub 2019 Aug 3.

28. Fabian P., McDevitt JJ, DeHaan WH. Influenza virus in human exhaled breath: an observational study. PLoS One 2008,3, e2691.

29. Geissmann F, Manz MG, Jung S. et al. Development of monocytes, macrophages and dendritic cell. Science. 2010 February 5; 327(5966): 656-661.

30. Dickinson AJ, Meyer M, Pawlak EA. et al. Analysis of sphingosine kinase activity in single natural killer cells from peripheral blood. Integr Biol (Camb). 2015 April;7(4): 392-401.

31. Downey GP, Doherty DE, Schwab, B. et al. Retention of leukocytes in capillaries: role of cell size and deformability. J Appl Physiol (1990) 69:17671778.

32. Park WB, Perera RA, Choe PG, Lau EH, Choi SJ, Chun JY, Oh HS, Song $\mathrm{KH}$, Bang JH, Kim ES, et al. Kinetics of serologic responses to MERS coronavirus infection in humans, South Korea. Emerg. Infect. Dis. 2015;21:2186-2189.

33. Misharin AV, Morales-Nebreda L, Reyfman PA, et al. Monocyte-derived alveolar macrophages drive lung fibrosis and persist in the lung over the life span. J Exp Med. 2017 Aug 7; 214(8): 2387-2404.

34. Janssen WJ, Stefanski AL, Bochner BS et al. Control of Lung Defense by Mucins and Macrophages: Ancient defense mechanisms with modern functions. Eur Respir J. 2016 October; 48(4):1201-1214.

35. Pober JS and Sessa WC. Inflammation and the Blood Microvascular System. Cold Spring Harb Perspect Biol 2015;7:a016345

36. Mercer BA, Lemaître V, Powell CA, and D'Armiento J. The Epithelial Cell in Lung Health and Emphysema Pathogenesis. Curr Respir Med Rev. 2006 May; 2(2): 101-142.

37. Lim YX, Ng YL, Tam JP and Liu DX. Review: Human Coronaviruses: A Review of Virus-Host Interactions. Diseases 2016, 4, 26. 
38. Alcami A, Koszinowski UH. Viral mechanisms of immune evasion. Immunol. Today 2000, 21,447-455.

39. Bowie AG, Unterholzner L. Viral evasion and subversion of patternrecognition receptor signalling. Nat. Rev. Immunol. 2008, 8, 911-922.

40. Ron D; Walter P. Signal integration in the endoplasmic reticulum unfolded protein response. Nat. Rev. Mol. Cell Biol. 2007, 8, 519-529.

41. Fung TS; Liu DX. Coronavirus infection, ER stress, apoptosis and innate immunity. Front. Microbiol. 2014,5,296.

42. Bortz WMT, Bortz WM 2nd. How fast do we age? Exercise performance over time as a biomarker. J Gerontol A Biol Sci Med Sci. 1996; 51:M223-5.

43. Goldspink DF. Ageing and activity: Their effects on the functional reserve capacities of the heart and vascular smooth and skeletal muscles. Ergonomics. 2005;48:1334-51.

44. Sehl ME, Yates FE. Kinetics of human aging: I. Rates of senescence between ages 30 and 70 years in healthy people. J Gerontol A Biol Sci Med Sci. 2001; 56:B198-208.

45. Shepherd JT, Rusch NJ, Vanhoutte PM. Effect of cold on the blood vessel wall. Gen Pharmacol. 1983;14(1):61-4.

46. Yeung PK, Wong JT. Inhibition of cell proliferation by mechanical agitati on involves transient cell cycle arrest at G1 phase in dinoflagellates. Protoplasma. 2003 Mar;220(3-4):173-8.

47. Schoeman D, Fielding BC. Coronavirus envelope protein: current knowledge. Virol J. 2019; 16: 69.

48. Hawryluck L, Gold WL, Robinson S, Pogorski S. Galea S, Styra R. SARS Control and Psychological Effects of Quarantine, Toronto, Canada. Emerg Infect Disv.10(7); 2004 JulPMC3323345, 10 (7),1206-12

49. Steptoe A, Hamer M, Chida Y. The effects of acute psychological stress on circulating inflammatory factors in humans: a review and meta-analysis. Brain Behav Immun. 2007 Oct;21((7)):901-12.

50. Segerstrom SC, Miller GE. Psychological stress and the human immune system: a meta-analytic study of 30 years of inquiry. Psychol Bull. 2004 Jul;130(4):601-30.

51. McCann SM. NY Acad Sci; 1997. Neuroimmunomodulation: Molecular aspects, integrative systems, and clinical advances. https://doi.org/10.1111/j.1749-6632.1998.tb09542.x 
52. Dhabhar FS. Effects of stress on immune function: the good, the bad, and the beautiful. Immunol Res. 2014 May;58(2-3):193-210.

53. Walburn J, Vedhara K, Hankins M, Rixon L, Weinman J. Psychological stress and wound healing in humans: a systematic review and meta-analysis. J Psychosom Res. 2009 Sep;67(3):253-71.

54. Webster Marketon JI, Glaser R. Stress hormones and immune function. Cell Immunol. 2008 Mar-Apr;252(1-2):16-26.

55. Allen AP, Kennedy PJ, Cryan JF, Dinan TG, Clarke G. Biological and psychological markers of stress in humans: focus on the Trier Social Stress Test. Neurosci Biobehav Rev. 2014 Jan;38:94-124.

56. Pedersen AF, Zachariae R, Bovbjerg DH. Psychological stress and antibody response to influenza vaccination: a meta-analysis. Brain Behav Immun. 2009 May;23(4):427-33.

57. Pedersen A, Zachariae R, Bovbjerg DH. Influence of psychological stress on upper respiratory infection-a meta-analysis of prospective studies. Psychosom Med. 2010 Oct;72(8):823-32.

58. Wu, Jianqing and Zha, Ping, Randomized Clinical Trial Is Biased and Invalid In Studying Chronic Diseases, Compared with Multiple Factors Optimization Trial (November 4, 2019). Available at SSRN:

https://ssrn.com/abstract=3480523 or http://dx.doi.org/10.2139/ssrn.3480523. https://www.researchgate.net/publication/336699251

59. Zheng J, Perlman S. Immune responses in influenza A virus and human coronavirus infections: An ongoing battle between the virus and host. Curr Opin Virol. 2018 Feb; 28: 43-52.

60. Nagata N, Iwata N, Hasegawa H, et al. Participation of both host and virus factors in induction of severe acute respiratory syndrome (SARS) in F344 rats infected with SARS coronavirus. Journal of Virology, 2007,81:1848-57.

61. Gutiérrez S, Michalakis Y, Blanc S. Population Bottlenecks During Within-Host Progression and Host-To-Host Transmission, Current Opinion in Virology, 2: 546-55.

62. Perlman S. and Netland J. Coronaviruses post-SARS: Update on replication and pathogenesis. Nat Rev Microbiol. 2009 June; 7(6):439-450.

63. Snawar Hussain, Tom Gallagher. SARS-Coronavirus Protein 6 Conformations Required to Impede Protein Import into the Nucleus. Virus Res. 2010 Nov; 153(2): 299-304.

64. Levander OA. Nutrition and Newly Emerging Viral Diseases: An Overview. Journal of Nutrition, 1997, 127(5 Suppl): 948S-950S. 
65. Beisel WR. Nutrition in Pediatric HIV Infection: Setting the Research Agenda. Nutrition and Immune Function: Overview. Journal of Nutrition, 1997, 126: 2611S-5S.

66. Beck MA. Selenium and Vitamin E Status: Impact on Viral Pathogenicity, Journal of Nutrition. 2007,137:1338-40.

67. Beck MA, Handy J, Levander OA. Host Nutritional Status: The Neglected Virulence Factor. Trends in Microbiology, 2004,12: 417-23

68. Beck MA, Levander OA, Handy J. Selenium Deficiency and Viral Infection, Jourrnal of Nutrition. 2003, 133:1463S-7S..

69. Alice M, Tang ES, Semba RD. (2013) "Nutrition and Infection", in: Kenrad E., Nelson C.M.W., editors. (eds.) Infectious Disease Epidemiology: Theory and Practice, 3rd eds. Burlington, MA: Jones \& Bartlett Learning.

70. Chandra RK. Nutrition and The Immune System: An Introduction, American Journal of Clinical Nutrition, 1997, 66: 460S-3S.

71. Keusch GT. The History of Nutrition: Malnutrition, Infection and Immunity, Journal of Nutrition 2003,133:336S-40S.

72. Nelson HK, Shi Q, Van Dael P, et al. Host Nutritional Selenium Status as a Driving Force for Influenza Virus Mutations. The FASEB Journal, 2001,15: 1846-8.

73. Ritz BW, Gardner EM. Malnutrition and Energy Restriction Differentially Affect Viral Immunity. Journal of Nutrition. 2006, 136: 1141-4.

74. Schaible UE, Kaufmann SH. Malnutrition and Infection: Complex Mechanisms and Global Impacts, PLoS Medicine, 2007, 4:e115.

75. Kanneganti TD, Dixit VD. Immunological Complications of Obesity, Nature Immunology, 2012, 13: 707-12.

76. Karlsson EA, Beck MA. Diet-Induced Obesity Impairs The T Cell Memory Response to Influenza Virus Infection. The FASEB Journal, 2009, 23: 110-3.

77. Karlsson EA, Sheridan PA, Beck MA. Diet-Induced Obesity Impairs the T Cell Memory Response to Influenza Virus Infection. The Journal of Immunology, 2010,184: 3127-33.

78. Mito N, Hosoda T, Kato C et al. Change of Cytokine Balance in DietInduced Obese Mice, Metabolism, 2000,49: 1295-300.

79. Monteiro R, Azevedo I. Chronic Inflammation in Obesity and the Metabolic Syndrome, Mediators of Inflammation, 10.1155/2010/289645 [epub ahead of print on July 14, 2010] 
80. Nieman DC, Henson DA, Nehlsen-Cannarella SL, et al. Influence of Obesity on Immune Function, Journal of the American Dietetic Association,1999, 99:294-9.

81. Kanneganti TD, Dixit VD. Immunological Complications of Obesity, Nat Immunol, 2012,13: 707-12.

82. Smith AG, Sheridan PA, Harp JB, et al. Diet-Induced Obese Mice have Increased Mortality and Altered Immune Responses when Infected with Influenza Virus, Journal of Nutrition, 2007, 37: 1236-43.

83. Aroor AR, DeMarco VG. Oxidative Stress and Obesity: The Chicken or the Egg? Diabetes, 2014, 63: 2216-8.

84. Barnett. JB, Hamer DH, Meydani SN. Zinc: a new risk factor for pneumonia in the elderly? Nutr Rev. Nutr Rev. 2010 Jan; 68(1): 30-37.

85. Bakunina N, Pariante CM, Zunszain PA. Immune mechanisms linked to depression via oxidative stress and neuroprogression. Immunology. 2015 Mar; 144(3): 365-373.

86. Dan Hu, Lei Wan, Michael Chen, Yi Caudle, Gene LeSage, Qinchuan Li, Deling Yin. Essential role of IL-10/STAT3 in chronic stress-induced immune suppression. Brain Behav Immun. 2014 Feb; 36: 118-127.

87. Cohen S, Janicki-Deverts D, Doyle WJ, Miller GE, Frank E, Rabin BS, et al. Chronic stress, glucocorticoid receptor resistance, inflammation, and disease risk. Proc Natl Acad Sci USA. 2012 Apr;109(16):5995-9. 